\title{
Mood instability, depression, and anxiety in pregnancy and adverse neonatal outcomes
}

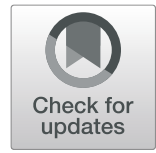

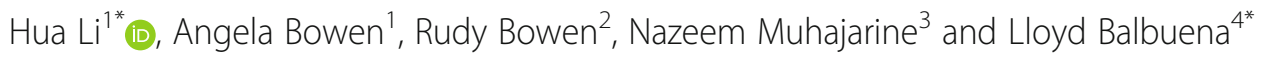

\begin{abstract}
Background: Antenatal women experience an increased level of mood and anxiety symptoms, which have negative effects on mothers' mental and physical health as well as the health of their newborns. The relation of maternal depression and anxiety in pregnancy with neonate outcomes is well-studied with inconsistent findings. However, the association between antenatal mood instability (MI) and neonatal outcomes has not been investigated even though antenatal women experience an elevated level of MI. We sought to address this gap and to contribute to the literature about pregnancy neonate outcomes by examining the relationship among antenatal $\mathrm{MI}$, depression, and anxiety and neonatal outcomes.

Methods: A prospective cohort of women $(n=555)$ participated in this study at early pregnancy $(T 1,17.4 \pm 4.9$ weeks) and late pregnancy (T2, $30.6 \pm 2.7$ weeks). The Edinburgh Postnatal Depression Scale (EPDS) was used to assess antenatal depressive symptoms, anxiety was measured by the EPDS anxiety subscale, and mood instability was measured by a visual analogue scale with five questions. These mood states together with stress, social support, as well as lifestyle were also examined in relation to neonatal outcomes using chi-square tests and logistic regression models.
\end{abstract}

Results: Mood instability, depression, and anxiety were unrelated to adverse neonatal outcomes. Only primiparous status was associated with small for gestational age after Bonferroni correction.

Conclusions: We report no associations between antenatal mood symptoms including Ml, depression, and anxiety and neonatal outcomes. More studies are required to further explore the relationship between antenatal mood instability, depression, and anxiety and neonatal outcomes.

Keywords: Antenatal women, Mood instability, Depression, Anxiety, Neonatal outcomes

\section{Background}

Pregnancy and childbirth are often viewed as joyful events, but they can also be overwhelming and challenging for some mothers. Becoming a mother is a vulnerable period for women to develop perinatal depression, anxiety [1, 2], postpartum blues, baby pinks [3], and mood instability (MI) [4, 5]. Perinatal women often

\footnotetext{
*Correspondence: hua.li@usask.ca; lloyd.balbuena@usask.ca

'College of Nursing, University of Saskatchewan, Health Sciences Building, E-Wing, Room 4248, 104 Clinic Place, SK S7N $2 Z 4$ Saskatoon, Canada

${ }^{4}$ Department of Psychiatry, University of Saskatchewan, Ellis Hall, RUH, Room 104, SK S7N OW8 Saskatoon, Canada

Full list of author information is available at the end of the article
}

experience the highest euphoric, irritable, and depressed moods in early pregnancy and again around the time of giving birth [6,7]. This phenomenon is thought to be triggered by the large hormonal fluctuations occurring at these times $[6,8,9]$.

Ample studies have found that not only do maternal depression and anxiety adversely affect a mother's physical and mental health, but also the infant's physical and cognitive development, and the mother-infant relationship, all of which endure into childhood and beyond [10]. The impact of antenatal depression or anxiety on neonatal outcomes has been investigated extensively in both developing and developed countries. However, the

C The Author(s). 2021 Open Access This article is licensed under a Creative Commons Attribution 4.0 International License, which permits use, sharing, adaptation, distribution and reproduction in any medium or format, as long as you give appropriate credit to the original author(s) and the source, provide a link to the Creative Commons licence, and indicate if changes were made. The images or other third party material in this article are included in the article's Creative Commons licence, unless indicated otherwise in a credit line to the material. If material is not included in the article's Creative Commons licence and your intended use is not permitted by statutory regulation or exceeds the permitted use, you will need to obtain permission directly from the copyright holder. To view a copy of this licence, visit http://creativecommons.org/licenses/by/4.0/. The Creative Commons Public Domain Dedication waiver (http://creativecommons.org/publicdomain/zero/1.0/) applies to the data made available in this article, unless otherwise stated in a credit line to the data. 
findings are inconsistent. Some studies have found a significant relationship between antenatal depression or anxiety and low birth weight (LBW), preterm birth (PTB), small for gestational age (SGA), or low Apgar score [11-14], while others have not [15-18]. These inconsistent findings could result from differences in methodological factors including measurements, the timing of assessments, composition of samples, and other confounders $[19,20]$.

In addition to depression and anxiety, mood instability has been found to be a prominent feature of pregnant and postpartum women. For example, in a longitudinal study, Bowen, A. et al. [21] investigated MI in a group of pregnant women into early postpartum compared to a control group of non-pregnant women with normal menstruum at 16 weeks, and 32 weeks of pregnancy, and 4 weeks of postpartum. The study found that perinatal women were more likely to experience MI (depressed, irritable, anxious, and euphoric moods). The relationship between MI and fluctuation of ovarian hormones has been studied largely under the concept of postpartum blues (PPB). The etiology of $\mathrm{PPB}$ is still undetermined although a biological underpinning - the rapid decline in ovarian hormones following delivery has been proposed [22]. However, the correlation of PPB with ovarian hormones is neither consistent nor wellstudied [23]. There is a lack of research regarding the relationship between perinatal MI and ovarian hormonal fluctuation.

Mood instability, defined as "rapid oscillations of intense affect, with a difficulty in regulating these oscillations" [24], has a prevalence of $13.9 \%$ among UK adults according to the Psychiatric Morbidity Survey [25]. The term MI is often used interchangeably with mood swings, affect instability, and emotional dysregulation $[24,26]$. With MI affecting a significant part of the population, its relation with both psychological and psychopathological traits has been examined including negative affect [27], low self-esteem [28], neuroticism [29]. There is growing recognition that MI increases the risk for an array of psychiatric disorders including depression and anxiety [30-32].

A recent study reported cross-sectional associations between MI and depression in early and late pregnancy, and $\mathrm{MI}$ in pregnancy predicted postpartum depression independently of antenatal depression [33]. In addition, Hapgood et al. [34] found that emotional lability observed in the early postpartum was a strong predictor of depression up to 14 months postpartum (13 weeks, 26 weeks, and 60 weeks). Although neonatal outcomes and antenatal depression and anxiety have been well-studied, we are not aware of any study that investigates the relationship between $\mathrm{MI}$ in pregnancy and neonatal outcomes.
In this study, we addressed the research gap and contribute to the literature about pregnancy neonate outcomes by examining the relationship among antenatal MI, depression, and anxiety and neonatal outcomes.

\section{Methods}

\section{Participants and procedure}

The current study was a secondary data analysis of the Feelings in Pregnancy and Motherhood Study (FIP) [33]. Maternal information was collected in early pregnancy (T1: $17.4 \pm 4.9$ weeks) and late pregnancy (T2: $30.6 \pm$ 2.7 weeks) while information of neonatal outcomes was obtained from the mothers and linked with hospital discharge records. The present study analyzed data from 555 mother-baby dyads. More information on the FIP can be found in a previous publication [33].

The Behavioural Research Ethics Board at the University of Saskatchewan has approved this study. All participants signed an informed consent form.

\section{Measures}

We assessed the symptoms of three constructs known in the literature to be closely related: MI, depression, and anxiety, making use of thresholds for clinical relevance.

\section{Depression}

Depressive symptoms were measured using the Edinburgh Postnatal Depression Scale (EPDS) at T1 and T2 [35]. The EPDS is the most widely used self-report measure for screening depression among pregnant and postpartum women $[36,37]$. Respondents select one of four possible responses (0-3) to each of ten questions to indicate how they felt in the previous week. Ratings for each item are summed for a possible maximum score of 30 (range 0-30; $0=$ not depressed, $30=$ highest score for depressive mood). Validation studies of the EPDS among antenatal women have shown a high degree of internal consistency (Cronbach's $\alpha=0.914$ ), and good convergent validity with the Beck Depression Inventory-I (rho $=0.850, p<0.001$ ) [38], while EPDS has been found to have a sensitivity of $77 \%$ and specificity of $94 \%$ [38]. In this study, attaining a score $\geq 12$ at either T1 or T2 was indicative of clinically significant depression [39].

\section{Anxiety}

Anxiety symptoms were measured at T1, and T2 using the EPDS anxiety subscale (items 3, 4, and 5) [40-43] with a score range of 0 to 9 . Among antenatal women, studies found that the anxiety subscale has an acceptable internal consistency (Cronbach's $\alpha=.77$ ) [44], and (Cronbach's $\alpha=.74$ ) respectively. In this study, we followed the recommended cut-off score of $\geq 6$ for community samples [45] as indicative of clinically significant anxiety. 


\section{Mood instability}

Mood instability was measured using five questions that were answered on a Visual Analogue Scale (VAS): 1 "mood frequent ups and downs", 2 "mood swings occur for no reason", 3 "other people complain about your mood swings", 4 "having trouble following through with plans because of mood swings", and 5 "not making commitments because moods might change" [33]. Each question is awarded a score ranging from 0 to 10 , and the higher score indicates a higher level of MI symptoms with a possible total score of 50 . We dichotomized MI scores into above and below the mean. This was done by calculating the average of T1 and T2 scores separately. If a woman's score was above the mean in either period, her MI symptom was coded 1 "High MI" and 0 "Low MI" otherwise.

\section{Other maternal variables}

Demographic, psychosocial, and pregnancy-related variables were also assessed. These included age $(<25$ vs $\geq$ 25 years), education attainment (< Grade 12 vs $\geq$ Grade 12), marital status (with or without a partner), ethnicity (aboriginal or not aboriginal), and annual family income ( $\leq 40 \mathrm{~K}$ vs $>40 \mathrm{~K})$. The psychosocial variables were sources of social support ( 1 or less vs 2 or more), the number of stressors (0-2 vs $>2$ ), partner support (i.e., is your partner supportive? yes or no), maternal smoking (yes or no), alcohol consumption (yes or no), and physical activity status (yes or no) during pregnancy were assessed. As we did with the mood variables, we classified a woman as having a risk factor if these were reported at either $\mathrm{T} 1$ or $\mathrm{T} 2$. We also used parity (primiparous vs multigravida) as a predictor variable.

\section{Neonatal outcome variables}

Neonatal outcome variables included one- and fiveminute Apgar scores, low birth weight (LBW), small for gestational age (SGA), and preterm birth (PTB). We dichotomized the Apgar scores based on previous studies [46, 47]. Apgar scores reflect a baby's wellbeing at birth by assessing five areas: activity, pulse, grimace, appearance, and respiration [48]. Each area is rated from 0 to 2 with a possible score of 10 (scores 7 or above indicate that the baby is doing well). Apgar scores were dichotomized into below normal $<7$ or normal $\geq 7$ [48]. Birth weight was measured in grams (g) and dichotomized into two levels: low $<2500$ g or normal $\geq 2500$ g [49]. SGA was defined as the infant with birth weight below the $10^{\text {th }}$ percentile of mean body weight of the infants of same gestational age and same gender [50]. Preterm birth is based on the duration of pregnancy in completed weeks from the first day of the last normal menstrual period to birth. The variable was dichotomized into preterm birth (PTB) $(<37$ weeks) and normal term birth $(\geq$ 37 weeks) [51].

\section{Data analysis}

We cross-tabulated nine maternal variables in pregnancy with the five neonatal outcomes. Chi-square or Fisher's exact test was used to examine the association of each maternal variable and each neonatal outcome (45 tests in all). To protect against false positive results from a large number of tests, we set $\alpha$ at .001 for each test (i.e., family-wise $\alpha=.05$ ). For each result that was significant at 0.001 , we created a logistic regression model that adjusted for maternal age category and marital status. Each logistic regression model was performed first, with complete cases and then with multiple imputations. Coefficients in logistic regression models were exponentiated to yield odds ratios (OR), and their 95\% confidence intervals (CI) were calculated accordingly. Multiple imputation was necessary because some variables (SGA, Apgar 1 minute, Apgar 5 minute, LBW, pregnancy stress, and maternal age category) had missing values that ranged from less than 1 to 17 percent. Multiple imputation is a principled way of avoiding biased estimates that can result from non-random missingness and overly narrow confidence intervals [52]. For sensitivity analysis, logistic regression was repeated with modification that the independent variables (depression, anxiety, and MI) were treated as continuous variables.

Statistical analyses were performed using Stata and imputation was carried out using multiple imputation with chained equations (MICE) [53]. We created 20 imputed datasets following the recommendation of White and colleagues [54].

\section{Results}

\section{Characteristics of the mothers and babies}

A total of 555 women participated in this study with a mean age of 29.0 years $(S D=4.85)$, and $38 \%(\mathrm{n}=212)$ were first-time mothers. Most of the women lived with a partner, had a Grade 12 or higher education, and had a family income of at least $\$ 40,000$. Sixty-eight babies (12\%) had a 1-minute Apgar score < 7, while 15 (3\%) babies had a 5-minute Apgar of $<7$. Only $20(4 \%)$ of the babies' birth weight was $<2500$ g, while 39 babies $(7 \%)$ were SGA. Thirty-two babies were born preterm $(6 \%)$ (Table 1).

One hundred and nine women $(20 \%)$ were screened positive for depression according to the cut-off 12 or more on EPDS, 118 (21\%) experienced high anxiety (EPDS anxiety subscale score $\geq 6$ ), and 283 (51\%) had an above average MI score. Approximately $1 / 3$ of women exercised regularly, while over $90 \%$ of women received partner support. Over half of women $(\mathrm{n}=304)$ experienced stress, while $10 \%$ of $(n=57)$ and $13 \%$ of $(n=72)$ used alcohol and smoked cigarettes respectively (Table $1)$. 
Table 1 Characteristics of mothers and infants ( $N=555)$

\begin{tabular}{|c|c|c|}
\hline Mothers & Number & Percent \\
\hline \multicolumn{3}{|l|}{ Demographic variables } \\
\hline Age $(\geq 25)$ & 465 & 84 \\
\hline Living with a partner & 504 & 91 \\
\hline Aboriginal ancestry & 42 & 8 \\
\hline Grade 12 or above & 529 & 95 \\
\hline Family income $>\$ 40,000$ & 263 & 90 \\
\hline \multicolumn{3}{|l|}{ Mood symptoms } \\
\hline Clinically significant depression & 109 & 20 \\
\hline Clinically significant anxiety & 118 & 21 \\
\hline Above-average mood instability & 283 & 51 \\
\hline \multicolumn{3}{|l|}{ Psychosocial and behaviour variables } \\
\hline Engaged in regular physical activity & 379 & 32 \\
\hline Alcohol use & 57 & 10 \\
\hline Cigarettes smoking & 72 & 13 \\
\hline With partner's support & 516 & 93 \\
\hline Stress & 304 & 55 \\
\hline First-time mothers & 212 & 38 \\
\hline \multicolumn{3}{|l|}{ Infants } \\
\hline \multicolumn{3}{|l|}{ Neonatal outcome variables } \\
\hline Apgar 1 minute score $<7^{a}$ & 68 & 12 \\
\hline Apgar 5 minute score $<7^{\text {a }}$ & 15 & 3 \\
\hline Pre-term birth $(<37 \text { weeks })^{b}$ & 32 & 6 \\
\hline Low birth weight $(<2.5 \mathrm{~kg})^{\mathrm{b}}$ & 20 & 4 \\
\hline Small for gestational age ${ }^{b}$ & 39 & 7 \\
\hline
\end{tabular}

a Had $17 \%$ missing values

${ }^{\mathrm{b}} \mathrm{Had} 10 \%$ missing values

The results of Cronbach's $\alpha$ for MI questionnaire are 0.886 at $\mathrm{T} 1$ and 0.837 at T2, for EPDS are 0.843 at $\mathrm{T} 1$ and 0.781 at $\mathrm{T} 2$, and for EPDS anxiety subscale are 0.726 at T1 and 0.702 at T2, indicating good or acceptable internal consistency for the measures.

\section{Mood instability, depression, anxiety, other maternal factors, and neonatal outcomes}

For the univariate logistic regression, anxiety in pregnancy was associated with Apgar (5-minute) scores below $7\left(x^{2}=3.78, p=.05\right)$, while stress was associated with low Apgar scores (1-minute) $\left(x^{2}=5.09, p=.02\right)$. Smoking, lack of partner support, and primiparous status were each associated with SGA $\left(\chi^{2}=10.05, p=.002\right.$; $\chi^{2}=7.63, p=.006 ; \chi^{2}=13.25, p<.001$ respectively). In addition, primiparous status was associated with LBW $\left(x^{2}=4.50, p=.03\right)$. Mood instability, depression, alcohol use, and exercise during pregnancy were not associated with any of the neonatal outcomes, while PTB was not associated with any maternal variables. The complete crosstabulation of maternal variables and neonate outcomes is presented in Table 2 .

In sensitivity analysis, we repeated univariate logistic analysis by treating independent variables of depression, anxiety, and MI as continuous variables, and the results of associations between neonatal outcomes and depression, anxiety, and MI were non-significant (Supplementary Table 1).

After Bonferroni correction, only parity status and SGA were significantly associated (See Table 2). We created a logistic regression model with SGA as the outcome variable and parity status as the single predictor, adjusting for maternal age and partner status. We did this both for complete cases and with multiple imputation. Both types of analysis showed that primiparous women were more than three times as likely (OR: 3.31 , 95\% CI: 1.66-6.59; OR: 3.27, 95\% CI: 1.62-6.62; respectively) to have babies with SGA compared to multigravida (See Table 3).

We then examined the possible relationships between neonatal outcomes and MI, depression, and anxiety while treating MI, depression, and anxiety as continuous variables. Similarly, we performed this procedure for complete cases and with multiple imputation. None of the three variables was associated with any adverse neonatal outcome, in either type of analysis (see Supplementary Table 1).

The associations between the other variables (i.e., age, marital status, ethnic background, education level, financial status, physical activities, and alcohol use) and neonatal outcomes were not significant.

\section{Discussion}

To the best of our knowledge, this is the first study to report the relationship between antenatal MI and neonatal outcomes. We did not find any association between neonatal outcomes and MI, antenatal depression, and anxiety. The lack of research on perinatal MI and its effects on the developing fetus limits our ability to discuss the findings in relation to other literature, but the growing research on the relationship of MI with depression, and anxiety serves as a basis for the discussion.

\section{Shared properties among mood instability, depression, and anxiety}

The fact of non-significant relationships among antenatal MI, depression, anxiety, and neonate outcomes may contribute to the argument that depression, anxiety, and MI share some common properties. First, comorbidity. Depression and anxiety comorbid in $63-67 \%$ of the patients with major depressive disorder in non-perinatal women [55], while a study of 4,451 postpartum women in the US reported that of the $18 \%$ of women who experienced anxiety, $35 \%$ also reported postpartum 
Table 2 Cross-tabulation of adverse neonatal outcomes by maternal variables (entries are percentages (\%))

\begin{tabular}{|c|c|c|c|c|c|c|}
\hline Variables & Measure & $\begin{array}{l}\text { Apgar } 1 \text { minute } \\
\text { score }<7^{\mathrm{a}}\end{array}$ & $\begin{array}{l}\text { Apgar } 5 \text { minute } \\
\text { score }<7^{a}\end{array}$ & $\begin{array}{l}\text { Pre-term birth }(< \\
37 \text { weeks) }\end{array}$ & $\begin{array}{l}\text { Low birth weight } \\
(<2.5 \mathrm{~kg})^{\mathrm{b}}\end{array}$ & $\begin{array}{l}\text { Small for } \\
\text { gestational age }^{b}\end{array}$ \\
\hline \multirow[t]{2}{*}{ Depression } & EPDS $<12$ & 14.78 & 3.23 & 6.39 & 4.36 & 8.11 \\
\hline & $E P D S \geq 12$ & 14.61 & 3.37 & 6.45 & 2.13 & 6.52 \\
\hline \multirow[t]{2}{*}{ Anxiety } & $\begin{array}{l}\text { EPDS Anxiety } \\
\text { subscale }<6\end{array}$ & 13.86 & 2.45 & 6.03 & 3.72 & 7.79 \\
\hline & $\begin{array}{l}\text { EPDS Anxiety } \\
\text { subscale } \geq 6\end{array}$ & 18.28 & 6.45 & 7.84 & 4.81 & 7.92 \\
\hline \multirow[t]{2}{*}{ Mood instability } & $\leq$ average & 14.03 & 3.62 & 6.02 & 4.00 & 8.84 \\
\hline & $>$ average & 15.48 & 2.93 & 6.80 & 3.91 & 6.83 \\
\hline \multirow[t]{2}{*}{ Alcohol use } & Not at all & 14.22 & 3.61 & 6.21 & 4.16 & 7.98 \\
\hline & Yes, at some point & 20.00 & 0.00 & 8.33 & 2.04 & 6.38 \\
\hline \multirow[t]{2}{*}{ Smoking } & No & 15.11 & 3.36 & 6.05 & 3.76 & 6.50 \\
\hline & Yes & 11.36 & 2.27 & 9.26 & 5.45 & 18.87 \\
\hline \multirow[t]{2}{*}{ Stress } & $0-2$ stressors & 10.75 & 3.29 & 6.99 & 4.29 & 9.57 \\
\hline & $3+$ stressors & 18.22 & 3.23 & 5.90 & 3.65 & 6.32 \\
\hline \multirow[t]{2}{*}{ Partner support } & Yes & 14.48 & 3.22 & 5.94 & 3.77 & 7.01 \\
\hline & No & 19.23 & 3.85 & 13.79 & 6.90 & 21.43 \\
\hline \multirow{2}{*}{$\begin{array}{l}\text { Parity (First-time } \\
\text { mothers) }\end{array}$} & No & 14.09 & 3.09 & 5.71 & 2.52 & $4.46^{*}$ \\
\hline & Yes & 15.88 & 3.53 & 7.57 & 6.32 & $13.51^{*}$ \\
\hline \multirow[t]{2}{*}{ Exercise } & Yes & 14.60 & 2.84 & 7.56 & 4.89 & 8.72 \\
\hline & No & 15.07 & 4.17 & 3.85 & 1.89 & 5.81 \\
\hline
\end{tabular}

${ }^{\mathrm{a}} 17 \%$ missing values, ${ }^{\mathrm{b}} 10 \%$ missing values

${ }^{*} p<0.001$ (significant after Bonferroni correction)

depressive symptoms [56]. The comorbidity between MI and depression was estimated to be $60.9 \%$ according to a population study administrated in the UK [57]. Second, neuroticism and negative affect. Studies that examined the positive relationship of MI with depression and anxiety in general and clinical samples have explained by alluding to shared correlates: neuroticism and trait negative affect (NA) [32, 58, 59]. For example, MI is a core feature of neuroticism and also has a strong link with trait NA that are identified as risk factors for both depression and anxiety [27, 60]. Some have suggested that individual differences in neuroticism and NA are central to understanding comorbidity among psychopathologies (e.g., depression, anxiety) [27, 29, 61-63]. Third, stress. The comorbidity between depression and anxiety has been conceptualized in a tripartite model
[64]. The model suggests that depression and anxiety have their distinct symptoms, for example, anhedonia for depression and hyperarousal for anxiety, but they share a central common 'distress' component. The shared general distress factor is manifested both as a transient state and as a more stable trait [64], and is in line with an internalizing factor in depression, generalized anxiety, and social anxiety [65-67]. Possible bidirectional effects between stress and MI have been proposed. As extreme shifts in mood that last from a few hours to a few days, MI may be a result of interpersonal stress, and high levels of MI may also lead to stressful life events (e.g., the break-up of a relationship, loss of a job) [59]. Fourth, emotion dysregulation. Studies revealed that emotion dysregulation appears to play an important role in anxiety and depressive disorders.

Table 3 Odds ratios (95\% Cl's) from logistic regression model of SGA with parity status as independent variable (adjusted for mother's age and marital status)

\begin{tabular}{|c|c|c|c|}
\hline Model & Predictor & Type of analysis & $\begin{array}{l}\text { Small for } \\
\text { gestational agef } \\
(\text { OR }(95 \% \mathrm{Cl}))\end{array}$ \\
\hline 1 & Parity (Primiparous) & Complete cases (n 461) & $3.31(1.66-6.59)^{*}$ \\
\hline 2 & & Multiply imputed data $(n=499)$ & $3.27(1.62-6.62)^{*}$ \\
\hline
\end{tabular}

${ }^{\ddagger} 10 \%$ missing values

${ }^{*} p<0.05$ 
For example, emotion dysregulation may create cognitive and functional difficulties in individuals with anxiety and/or depression, such as decreased awareness, poor understanding, inhibited or inappropriate expression, and difficulty managing emotions $[68,69]$.

\section{Relation to previous studies}

Antenatal depression and anxiety were not associated with adverse neonatal outcomes in the current study that is in agreement with prior studies [16, 18, 20, 70], whereas other studies have reported significant relationships between them $[12,19,71]$. The major reasons for the inconsistent findings might be related to differences in methodology, measurements, sample size or composition, the timing of assessment of depression and anxiety, settings, and variation in accounted for potential confounders [19, 20, 72].

Being primiparous was identified as a significant risk factor for SGA (both in complete-case and multiply imputed data) in the current study, which is consistent with some previous studies [73, 74]. A meta-analysis of 41 studies found that being primiparous increased a woman's risk of having a baby with LBW and SGA [73]. Parity influences the growth of the placenta and its efficiency, which is related to uterine blood flow, oxygen availability, nutrient exchange, and endocrine regulation of the fetus [74, 75].

\section{Implications}

From a clinical practice perspective, clinicians tend to focus on depression and anxiety. Mood instability is not routinely assessed in a check-up for perinatal women, perhaps due to the perception of perinatal MI as a normal part of a woman's life, and the propensity for investigating only diagnostic conditions. However, given the evidence of perinatal women experiencing a higher level of MI, a strong link between MI and depression and anxiety in non-perinatal populations [30, 76], and correlation of MI with depression among perinatal women cross-sectionally and prospectively, antenatal MI has the potential to be a risk factor for antenatal depression and anxiety. Therefore, routine screening of MI in clinical and primary healthcare settings may identify women who are at risk for developing depression or anxiety, which could provide another opportunity for prevention, early detection, and early intervention of mood symptoms in perinatal women. As mothers' mental health has a profound impact on neonatal outcomes and child mental and physical health, more research is required to further understand mood states in pregnancy and neonatal outcomes including longitudinal studies with larger sample sizes.

\section{Limitations}

First, although this is a relatively large sample, the participants were predominantly Caucasian, married, with post-secondary education, and with higher family income, which limits the generalization of the findings. According to the 2016 Census of Canada [77], Indigenous people accounted for $15.6 \%$ of the total population of Saskatchewan compared with $7.2 \%$ in this sample. Second, our results might not be generalizable to other populations, particularly those with higher rates of preterm birth and malnutrition during pregnancy $[78,79]$. Third, for the data analysis, there were cell sizes below 20 for low birth weight $\mathrm{x}$ depression and for low birth weight $\mathrm{x}$ exercise. The non-significant associations for these variables could be a result of inadequate power due to the low sample size. To better understand the adequacy of the sample, we performed a posthoc power analysis of our logistic regression models and found that the effect sizes of our predictors needed to be 20 percent or greater. MI, depression, and anxiety reached this effect size for at least one adverse outcome, but not for the majority. In adjusting for multiple comparisons, some of our findings were no longer significant, so replication of our analysis with larger samples of motherinfant dyads, and focusing on only a few key factors/determinants, may help to identify whether there are in fact differences/associations. Fourth, the measure of depression, anxiety, MI, and other psychosocial and behaviour variables relied on participants' subjective report, which could be influenced by women's current thoughts, feelings, and consideration of social desirability particularly, reporting antenatal smoking, alcohol consumption, and drug use [80, 81]. Fifth, MI holds a temporal property since mood fluctuations can change from moment to moment, which is unlikely to be recalled accurately, such as which day and what time during the day it occurred [82]. Different methods have been used to capture the rapid shift of moods (MI) including Ecological Momentary Assessment and smartphone [83, 84]. Finally, the VAS used to assess antenatal MI is not previously validated. Due to a lack of validated instruments in measuring perinatal MI, studies often utilize nonvalidated measures [21, 34]. There is a need for validating existing instruments in perinatal women or developing assessment tools that are specifically relevant to perinatal MI.

\section{Conclusion}

The current study expands our knowledge on mood and anxiety symptoms during pregnancy, and their relations to neonatal outcomes. Antenatal MI, depression, and anxiety were not found to be risk factors for adverse neonatal outcomes in a country with well-developed welfare systems. Further studies are needed to explore associations with healthcare accessibility and utilization during pregnancy, and possible long-term effects of maternal MI on children's development. 


\section{Abbreviations}

AGA: Appropriate for gestational age.; Cl: Confidence intervals.;

EPDS: Edinburgh Postnatal Depression Scale.; FIP: Feelings in Pregnancy and Motherhood Study.; g: Grams.; LBW: Low birth weight:; LGA: Large for gestational age.; MI: Mood instability.; N: Sample size.; OR: Odds ratios.; PTB: Preterm birth.; SD: Standard deviation.; SGA: Small for gestational age.; T1: Early pregnancy: $17.4 \pm 4.9$ weeks.; T2: Late pregnancy:30.6 \pm 2.7 weeks.; VAS: Visual Analogue Scale.

\section{Supplementary Information}

The online version contains supplementary material available at https://doi. org/10.1186/s12884-021-04021-y.

Additional file 1: Supplementary Table 1. Odds ratios (95\% Cls) in

models with continuous independent variables.

\section{Acknowledgments}

The authors would like to thank the women who participated in this study.

\section{Authors' contributions}

HL overviewed current literature on the topic, analyzed the data, interpreted results, and wrote the initial manuscript draft; $A B$ and $N M$ originally designed the study and gathered the data; $A B, R B$, and $L B$ provided expertise and appraisal of available data; $L B$ analyzed the data, $A B, R B, L B$, and $N M$ provided the interpretation of results and provided an overview of current literature on the topic, and AB provided supervision. LB revised the initial draft. $L B$ and $H L$ revised the paper after peer review. All the authors contributed comments and approved the final version.

\section{Funding}

This work was supported by the Canadian Institutes of Health Research (Grant \# 145179). The funding agency had no role in the design, data collection, analysis, interpretation, and writing of the study.

\section{Availability of data and materials}

The datasets used and analyzed in this study are available from the corresponding author on reasonable request.

\section{Declarations}

\section{Ethics approval and consent to participate}

Ethics approval for the research protocol was obtained from the Behavioural Research Ethics Board at the University of Saskatchewan (Beh \# 16-267). Written informed consent was obtained from women before they participated in the study.

\section{Consent for publication}

Not applicable

\section{Competing interests}

The authors declare that they have no competing interests.

\section{Author details}

${ }^{1}$ College of Nursing, University of Saskatchewan, Health Sciences Building, E-Wing, Room 4248, 104 Clinic Place, SK S7N $2 Z 4$ Saskatoon, Canada. 2Department of Psychiatry, University of Saskatchewan, Ellis Hall, RUH, Room 112, SK S7N 0W8 Saskatoon, Canada. ${ }^{3}$ Department of Community Health and Epidemiology, University of Saskatchewan, Health Sciences Building, E-Wing, Room 3246104 Clinic Place, SK S7N $2 Z 4$ Saskatoon, Canada. ${ }^{4}$ Department of Psychiatry, University of Saskatchewan, Ellis Hall, RUH, Room 104, SK S7N OW8 Saskatoon, Canada.

Received: 16 August 2020 Accepted: 27 July 2021

Published online: 25 August 2021

\section{References}

1. Kessler RC, Berglund P, Demler $\mathrm{O}$, Jin R, Koretz D, Merikangas KR, et al. The epidemiology of major depressive disorder: results from the National
Comorbidity Survey Replication (NCS-R). JAMA. 2003;289(23):3095-105. https://doi.org/10.1001/jama.289.23.3095.

2. Milgrom J, Gemmill AW. Screening for perinatal depression. Best Pract Res Clin Obstet Gynaecol. 2014;28(1):13-23. https://doi.org/10.1016/j.bpobgyn.2 013.08.014.

3. Maliszewska K, Swiatkowska-Freund M, Bidzan M, Preis K. Relationship, social support, and personality as psychosocial determinants of the risk for postpartum blues. Ginekol Pol. 2016;87(6):442-7. https://doi.org/10.5603/ GP.2016.0023

4. Pop V, Truijens SE, Spek V, Wijnen HA, Van Son MJ, Bergink V. A new concept of maternity blues: Is there a subgroup of women with rapid cycling mood symptoms? J Affect Disord. 2015;177:74-9.

5. Reck C, Stehle E, Reinig K, Mundt C. Maternity blues as a predictor of DSMIV depression and anxiety disorders in the first three months postpartum. J Affect Disord. 2009:113(1):77-87.

6. Cunningham F, Leveno K, Bloom S, Hauth J, Rouse D, Spong C. Williams Obstetrics 23rd Edition vol. 872. New York, US: McGraw Hill: 2010.

7. Steiner M, Dunn E, Born L. Hormones and mood: from menarche to menopause and beyond. J Affect Disord. 2003;74(1):67-83. https://doi.org/1 0.1016/50165-0327(02)00432-9.

8. Buttner MM, O'Hara MW, Watson D. The structure of women's mood in the early postpartum. Assessment. 2012;19(2):247-56. https://doi.org/10.1177/1 073191111429388.

9. Fooladi MM. Therapeutic tears and postpartum blues. Holist Nurs Pract. 2006;20(4):204-11. https://doi.org/10.1097/00004650-200607000-00009.

10. O'hara MW, McCabe JE. Postpartum depression: current status and future directions. Annu Rev Clin Psychol. 2013;9:379-407. https://doi.org/10.1146/a nnurev-clinpsy-050212-185612.

11. Nasreen HE, Kabir ZN, Forsell Y, Edhborg M. Low birth weight in offspring of women with depressive and anxiety symptoms during pregnancy: results from a population based study in Bangladesh. BMC Public Health. 2010; 10(1):515. https://doi.org/10.1186/1471-2458-10-515.

12. Goedhart G, Snijders AC, Hesselink AE, van Poppel MN, Bonsel GJ, Vrijkotte TG. Maternal depressive symptoms in relation to perinatal mortality and morbidity: results from a large multiethnic cohort study. Psychosom Med. 2010;72(8):769-76. https://doi.org/10.1097/PSY.0b013e3181ee4a62

13. Field T, Diego M, Hernandez-Reif M, Figueiredo B, Schanberg S, Kuhn C, et al. Chronic prenatal depression and neonatal outcome. Int J Neurosci. 2008;118(1):95-103. https://doi.org/10.1080/00207450601042144.

14. Saeed A, Raana T, Saeed AM, Humayun A. Effect of antenatal depression on maternal dietary intake and neonatal outcome: a prospective cohort. Nutr J. 2016;15(1):64. https://doi.org/10.1186/s12937-016-0184-7.

15. Evans J, Heron J, Patel RR, Wiles N. Depressive symptoms during pregnancy and low birth weight at term. Br J Psychiatry. 2007;191(1):84-5. https://doi. org/10.1192/bjp.bp.105.016568.

16. Andersson L, Sundström-Poromaa I, Wulff M, Åström M, Bixo M. Neonatal outcome following maternal antenatal depression and anxiety: a population-based study. Am J Epidemiol. 2004;159(9):872-81. https://doi. org/10.1093/aje/kwh122.

17. Neggers $Y$, Goldenberg R, Cliver S, Hauth J. The relationship between psychosocial profile, health practices, and pregnancy outcomes. Acta Obstet Gynecol Scand. 2006;85(3):277-85. https://doi.org/10.1080/0001634 0600566121.

18. Flynn HA, McBride N, Cely A, Wang Y, DeCesare J. Relationship of prenatal depression and comorbidities to infant outcomes. CNS Spectrums. 2015; 20(1):20-8. https://doi.org/10.1017/S1092852914000716.

19. Li D, Liu L, Odouli R. Presence of depressive symptoms during early pregnancy and the risk of preterm delivery: a prospective cohort study. Hum Reprod. 2008;24(1):146-53. https://doi.org/10.1093/humrep/den342.

20. Berle J, Mykletun A, Daltveit AK, Rasmussen S, Holsten F, Dahl AA. Neonatal outcomes in offspring of women with anxiety and depression during pregnancy. Arch Womens Mental Health. 2005;8(3):181-9. https://doi.org/1 0.1007/s00737-005-0090-z.

21. Bowen A, Bowen R, Balbuena L, Muhajarine N. Are pregnant and postpartum women moodier? Understanding perinatal mood instability. J Obstet Gynaecol Can. 2012;34(11):1038-42. https://doi.org/10.1016/S1 701-2163(16)35433-0.

22. Glover V. Maternal depression, anxiety and stress during pregnancy and child outcome; what needs to be done. Best Pract Res Clin Obstetrics Gynaecol. 2014;28(1):25-35. https://doi.org/10.1016/j. bpobgyn.2013.08.017. 
23. Henshaw C. Mood disturbance in the early puerperium: a review. Arch Womens Ment Health. 2003:6 Suppl 2(2):S33-42. https://doi.org/10.1007/ s00737-003-0004-x

24. Marwaha S, He Z, Broome M, Singh SP, Scott J, Eyden J, et al. How is affective instability defined and measured? A systematic review. Psychol Med. 2014:44(9):1793-808.

25. Marwaha S, Parsons N, Flanagan S, Broome M. The prevalence and clinical associations of mood instability in adults living in England: results from the Adult Psychiatric Morbidity Survey 2007. Psychiatry Res. 2013;205(3):262-8. https://doi.org/10.1016/j.psychres.2012.09.036.

26. Links PS, Eynan R, Heisel MJ, Nisenbaum R. Elements of affective instability associated with suicidal behaviour in patients with borderline personality disorder. Can J Psychiatry. 2008;53(2):112-6. https://doi.org/10.1177/0706743 70805300206.

27. Miller D, Vachon DD, Lynam DR. Neuroticism, negative affect, and negative affect instability: Establishing convergent and discriminant validity using ecological momentary assessment. Personal Individ Differ. 2009;47(8):873-7. https://doi.org/10.1016/j.paid.2009.07.007.

28. Meier $L L$, Orth $U$, Denissen JJ, Kühnel A. Age differences in instability, contingency, and level of self-esteem across the life span. J Res Pers. 2011; 45(6):604-12. https://doi.org/10.1016/j.jrp.2011.08.008.

29. Miller J, Pilkonis PA. Neuroticism and affective instability: the same or different? Am J Psychiatr. 2006;163(5):839-45. https://doi.org/10.1176/ajp.2 006.163.5.839

30. Bowen R, Baetz M, Hawkes J, Bowen A. Mood variability in anxiety disorders. J Affect Disord. 2006;91(2-3):165-70. https://doi.org/10.1016/j.jad.2005.12.050.

31. Marwaha S, Balbuena L, Winsper C, Bowen R. Mood instability as a precursor to depressive illness: A prospective and mediational analysis. Aust N Z J Psychiatry. 2015;30(6):557-65. https://doi.org/10.1177/0004867415579920

32. Thompson RJ, Berenbaum H, Bredemeier K. Cross-sectional and longitudinal relations between affective instability and depression. J Affect Disord. 2011; 130(1):53-9. https://doi.org/10.1016/j.jad.2010.09.021.

33. Li H, Bowen A, Bowen R, Feng C, Muhajarine N, Balbuena L. Mood instability across the perinatal period: A cross-sectional and longitudinal study. J Affect Disord. 2020;264:15-23.

34. Hapgood CC, Elkind GS, Wright JJ. Maternity blues: phenomena and relationship to later post partum depression. Aust N Z J Psychiatry. 1988; 22(3):299-306. https://doi.org/10.3109/00048678809161211.

35. Cox JL, Holden JM, Sagovsky R. Detection of postnatal depression. Development of the 10-item Edinburgh Postnatal Depression Scale. Br J Psychiatry. 1987;150(6):782-6. https://doi.org/10.1192/bjp.150.6.782.

36. Gibson J, McKenzie-McHarg K, Shakespeare J, Price J, Gray R. A systematic review of studies validating the Edinburgh Postnatal Depression Scale in antepartum and postpartum women. Acta Psychiatr Scand. 2009;119(5):35064. https://doi.org/10.1111/j.1600-0447.2009.01363.x.

37. Alvarado R, Jadresic E, Guajardo V, Rojas G. First validation of a Spanishtranslated version of the Edinburgh postnatal depression scale (EPDS) for use in pregnant women. A Chilean study. Arch Womens Mental Health. 2015:18(4):607-12. https://doi.org/10.1007/s00737-014-0466-z

38. Rubertsson C, Börjesson K, Berglund A, Josefsson A, Sydsjö G. The Swedish validation of Edinburgh postnatal depression scale (EPDS) during pregnancy. Nord J Psychiatry. 2011;65(6):414-8.

39. Levis B, Negeri Z, Sun Y, Benedetti A, Thombs BD. Accuracy of the Edinburgh Postnatal Depression Scale (EPDS) for screening to detect major depression among pregnant and postpartum women: systematic review and meta-analysis of individual participant data. BMJ. 2020;371. https://doi. org/10.1136/bmj.m4022.

40. Buist A, Gotman N, Yonkers KA. Generalized anxiety disorder: course and risk factors in pregnancy. J Affect Disord. 2011;131(1):277-83. https://doi.org/10.1 016/j.jad.2011.01.003.

41. Bowen A, Bowen R, Maslany G, Muhajarine N. Anxiety in a socially high-risk sample of pregnant women in Canada. Can J Psychiatry. 2008;53(7):435-40.

42. Tuohy A, McVey C. Subscales measuring symptoms of non-specific depression, anhedonia, and anxiety in the Edinburgh Postnatal Depression Scale. Br J Clin Psychol. 2008:47(2):153-69.

43. Kabir K, Sheeder J, Kelly LS. Identifying postpartum depression: are 3 questions as good as 10? Pediatrics. 2008;122(3):e696-702.

44. Swalm D, Brooks J, Doherty D, Nathan E, Jacques A. Using the Edinburgh postnatal depression scale to screen for perinatal anxiety. Arch Womens Mental Health. 2010;13(6):515-22. https://doi.org/10.1007/ s00737-010-0170-6.
45. Matthey S. Using the Edinburgh Postnatal Depression Scale to screen for anxiety disorders. Depress Anxiety. 2008;25(11):926-31. https://doi.org/10.1 002/da.20415.

46. Regenbogen SE, Ehrenfeld JM, Lipsitz SR, Greenberg CC, Hutter MM, Gawande AA. Utility of the surgical apgar score: validation in 4119 patients. Arch Surg. 2009;144(1):30-6. https://doi.org/10.1001/archsurg.2008.504.

47. McCue Horwitz S, Briggs-Gowan MJ, Storfer-Isser A, Carter AS. Prevalence, correlates, and persistence of maternal depression. J Women's Health. 2007; 16(5):678-91.

48. Apgar V, Beck JW. Is my baby all right?: A guide to birth defects. New York, NY: Simon \& Schuster; 1972.

49. Wardlaw TM. Low birthweight: country, regional and global estimates: UNICEF; 2004

50. Kramer MS, Platt RW, Wen SW, Joseph KS, Allen A, Abrahamowicz M, et al. Fetal/Infant Health Study Group of the Canadian Perinatal Surveillance S: A new and improved population-based Canadian reference for birth weight for gestational age. Pediatrics. 2001;108(2):E35. https://doi.org/10.1542/ peds.108.2.e35.

51. Eisfeld J. International statistical classification of diseases and related health problems. TSQ: Transgender Studies Quarterly. 2014;1(1-2):107-10.

52. van Ginkel JR, Linting M, Rippe RCA, van der Voort A. Rebutting Existing Misconceptions About Multiple Imputation as a Method for Handling Missing Data. J Pers Assess. 2020;102(3):297-308. https://doi.org/10.1080/ 00223891.2018 .1530680

53. Royston P, White IR. Multiple Imputation by Chained Equations (MICE): Implementation in Stata. J Stat Softw. 2011;45(4):1-20.

54. White IR, Royston P, Wood AM. Multiple imputation using chained equations: Issues and guidance for practice. Stat Med. 2011;30(4):377-99. https://doi.org/10.1002/sim.4067.

55. Lamers F, van Oppen P, Comijs HC, Smit JH, Spinhoven P, van Balkom AJ, et al. Comorbidity patterns of anxiety and depressive disorders in a large cohort study: the Netherlands Study of Depression and Anxiety (NESDA). J Clin Psychiatry. 2011;72(3):341-8.

56. Farr SL, Dietz PM, O'Hara MW, Burley K, Ko JY. Postpartum anxiety and comorbid depression in a population-based sample of women. J Women's Health. 2014;23(2):120-8. https://doi.org/10.1089/jwh.2013.4438.

57. Marwaha S, Parsons N, Broome M. Mood instability, mental illness and suicidal ideas: results from a household survey. Soc Psychiatry Psychiatr Epidemiol. 2013;48(9):1431-7. https://doi.org/10.1007/s00127-013-0653-7.

58. Bowen R, Balbuena L, Baetz M, Marwaha S. Mood instability in people with obsessive compulsive disorder and obsessive-compulsive personality traits. J Obsessive Compulsive Relat Disord. 2015;6:108-13. https://doi.org/10.1016/j. jocrd.2015.07.003

59. Koenigsberg HW, Harvey PD, Mitropoulou V, Schmeidler J, New AS, Goodman $\mathrm{M}$, et al. Characterizing affective instability in borderline personality disorder. Am J Psychiatr. 2002;159(5):784-8. https://doi.org/10.11 76/appi.ajp.159.5.784.

60. Bowen R, Balbuena L, Leuschen C, Baetz M. Mood instability is the distinctive feature of neuroticism. Results from the British Health and Lifestyle Study (HALS). Personal Individ Differ. 2012;53(7):896-900. https:// doi.org/10.1016/j.paid.2012.07.003.

61. Quilty LC, Sellbom M, Tackett JL, Bagby RM. Personality trait predictors of bipolar disorder symptoms. Psychiatry Res. 2009;169(2):159-63. https://doi. org/10.1016/j.psychres.2008.07.004.

62. Bowen R, Baetz M, Leuschen C, Kalynchuk LE. Predictors of suicidal thoughts: Mood instability versus neuroticism. Personal Individ Differ. 2011; 51(8):1034-8. https://doi.org/10.1016/j.paid.2011.08.015

63. Denollet J, De Vries J. Positive and negative affect within the realm of depression, stress and fatigue: the two-factor distress model of the Global Mood Scale (GMS). J Affect Disord. 2006;91(2):171-80. https://doi.org/10.101 6/j.jad.2005.12.044

64. Clark LA, Watson D. Tripartite model of anxiety and depression: psychometric evidence and taxonomic implications. J Abnorm Psychol. 1991;100(3):316-36. https://doi.org/10.1037//0021-843x.100.3.316.

65. Lahey BB, Applegate B, Waldman ID, Loft JD, Hankin BL, Rick J. The structure of child and adolescent psychopathology: generating new hypotheses. J Abnorm Psychol. 2004;113(3):358. https://doi.org/10.1037/ 0021-843X.113.3.358.

66. Slade T, Watson D. The structure of common DSM-IV and ICD-10 mental disorders in the Australian general population. Psychol Med. 2006;36(11): 1593-600. 
67. Vollebergh WA, ledema J, Bijl RV, de Graaf R, Smit F, Ormel J. The structure and stability of common mental disorders: the NEMESIS study. Arch Gen Psychiatry. 2001;58(6):597-603. https://doi.org/10.1001/archpsyc.58.6.597.

68. McLaughlin KA, Hatzenbuehler ML, Mennin DS, Nolen-Hoeksema S. Emotion dysregulation and adolescent psychopathology: A prospective study. Behav Res Ther. 2011;49(9):544-54. https://doi.org/10.1016/j.brat.2011.06.003.

69. Southam-Gerow MA, Kendall PC. A preliminary study of the emotion understanding of youths referred for treatment of anxiety disorders. I Clin Child Psychol. 2000;29(3):319-27.

70. Larsson C, Sydsjö G, Josefsson A. Health, sociodemographic data, and pregnancy outcome in women with antepartum depressive symptoms. Obstet Gynecol. 2004;104(3):459-66. https://doi.org/10.1097/01.AOG.000013 6087.46864.e4

71. Dayan J, Creveuil C, Marks MN, Conroy S, Herlicoviez M, Dreyfus M, et al. Prenatal depression, prenatal anxiety, and spontaneous preterm birth: a prospective cohort study among women with early and regular care. Psychosom Med. 2006;68(6):938-46. https://doi.org/10.1097/01.psy.0000244 025.20549.bd

72. Gaynes BN, Gavin N, Meltzer-Brody S, Lohr KN, Swinson T, Gartlehner G, et al. Perinatal depression: Prevalence, screening accuracy, and screening outcomes: Summary. Evid Rep Technol Assessment (Summary). 2005;119:18.

73. Shah PS. Parity and low birth weight and preterm birth: a systematic review and meta-analyses. Acta Obstet Gynecol Scand. 2010;89(7):862-75.

74. Fowden A, Sferruzzi-Perri A, Coan P, Constancia M, Burton G. Placental efficiency and adaptation: endocrine regulation. J Physiol. 2009;587(14): 3459-72. https://doi.org/10.1113/jphysiol.2009.173013.

75. Roland MCP, Friis CM, Voldner N, Godang K, Bollerslev J, Haugen G, et al. Fetal growth versus birthweight: the role of placenta versus other determinants. PLoS One. 2012;7(6):e39324. https://doi.org/10.1371/journal. pone.0039324

76. Marwaha S, Balbuena L, Winsper C, Bowen R. Mood instability as a precursor to depressive illness: A prospective and mediational analysis. Aust New Zealand J Psychiatry. 2015;49(6):557-65.

77. Topics 2016 Census [http://www12.statcan.gc.ca/census-recensement/2016/ rt-td/index-eng.ffm]. Accessed 26 May 2019.

78. Abu-Saad K, Fraser D. Maternal nutrition and birth outcomes. Epidemiol Rev. 2010;32(1):5-25. https://doi.org/10.1093/epirev/mxq001.

79. Wen SW, Smith G, Yang Q, Walker M. Epidemiology of preterm birth and neonatal outcome. In: Seminars in Fetal and Neonatal Medicine: Elsevier; 2004. p. 429-35.

80. Van de Mortel TF. Faking it: social desirability response bias in self-report research. Aust J Adv Nurs. 2008;25(4):40.

81. Alvik A, Haldorsen T, Lindemann R. Consistency of reported alcohol use by pregnant women: anonymous versus confidential questionnaires with item nonresponse differences. Alcohol Clin Exp Res. 2005;29(8):1444-9. https:// doi.org/10.1097/01.alc.0000175014.31463.9a.

82. Fredrickson BL. Extracting meaning from past affective experiences: The importance of peaks, ends, and specific emotions. Cognit Emot. 2000;14(4): 577-606. https://doi.org/10.1080/026999300402808.

83. Peters EM, Dong LY, Thomas T, Khalaj S, Balbuena L, Baetz M, et al. Instability of Suicidal Ideation in Patients Hospitalized for Depression: An Exploratory Study Using Smartphone Ecological Momentary Assessment. Arch Suicide Res. 2020:1-14. https://doi.org/10.1080/13811118.2020.1783410.

84. Sperry SH, Kwapil TR. Comparing static and dynamic measures of affect intensity and affective lability: do they measure the same thing? Motiv Emot. 2020. https://doi.org/10.1007/s11031-020-09840-8.

\section{Publisher's Note}

Springer Nature remains neutral with regard to jurisdictional claims in published maps and institutional affiliations.

Ready to submit your research? Choose BMC and benefit from:

- fast, convenient online submission

- thorough peer review by experienced researchers in your field

- rapid publication on acceptance

- support for research data, including large and complex data types

- gold Open Access which fosters wider collaboration and increased citations

- maximum visibility for your research: over $100 \mathrm{M}$ website views per year

At BMC, research is always in progress.

Learn more biomedcentral.com/submissions 